\title{
AN AIR FIRING BASE METAL RESISTOR AND CONDUCTOR SYSTEM FOR LOW COST THICK FILM CIRCUIT MANUFACTURE
}

\author{
E. K. BROWNE and B. WALTON \\ Electrofilm Products Division, ERA Technology Ltd., Leatherhead, Surrey England
}

\begin{abstract}
A series of air-firing base metal resistor pastes which yield resistors with properties comparable to those of conventional precious metal thick film resistors has been developed. The pastes can be post-fired or co-fired with air-firing nickel conductors in a very fast firing cycle thus providing a base metal combination which can be processed using conventional furnaces. This is concluded to be a significant contribution to the manufacture of thick film circuits of low cost especially in view of recent large increases in the prices of precious metals.
\end{abstract}

\section{INTRODUCTION}

The thick film industry has been based on the use of resistor and conductor pastes containing precious metals and the use of these materials has become firmly established. The outstanding electrical conductivity and chemical inertness of noble metals are attributes which are well suited to the role of these elements in thick film technology. Unfortunately noble metals are expensive and their replacement by cheaper alternatives has long been a goal of paste technologists. Most attempts to produce base metal conductor and resistor systems have relied upon the use of reducing atmospheres in the thick film furnace to protect the metals from oxidation at high temperatures. This is a rather expensive and inconvenient procedure requiring specially designed furnaces. Furthermore the characteristics of the fired films are inferior to those obtainable with conventional materials fired in air. An air-firing base metal resistor system with promising properties which was developed in the authors' laboratory was first described by Laurie. ${ }^{1}$ The system was originally intended mainly for use with lower cost palladium-silver conductors containing relatively high proportions of silver. Now, with recent further steep increases in the price of precious metals the use of even these silver-rich compositions carries a significant cost penalty. There is therefore a strong incentive to introduce an all base-metal resistor and conductor system. The paper describes such a system which comprises an improved series of air firing resistor pastes fully compatible with air-firing nickel conductors.

\section{BASIS OF THE RESISTOR SYSTEM}

The original system described by Laurie consisted of a cadmium alumino borate glass containing as a dissolved component, molybdenum trioxide. During the firing cycle, after decomposition and removal of the organic vehicle, the glass melted and flowed together to form a continuous film. On further increasing the temperature, an electrically conducting phase, molybdenum dioxide, was precipitated by the action on the trioxide of a carefully chosen reducing agent. Thus the conducting oxide was completely protected from re-oxidation in the furnace atmosphere by total encapsulation in the glass phase. A filamentary network of interlocking needleshaped molybdenum dioxide crystals was formed and this filamentary structure provided the high degree of non-uniformity in the distribution of the conducting phase which is necessary to produce high resistance values. A range of resistance values was obtained essentially by varying the concentration of the conducting phase in the surrounding non-conducting glassy matrix.

This basic system has been modified and refined to improve the properties and to extend the range in order to develop an attractive commercial system. (Electrofilm Series R1000 resistor Pastes).

\section{PROPERTIES OF THE FIRED RESISTORS}

The basic characteristics of resistors fired on $96 \%$ alumina substrate with palladium silver terminations 
TABLE I

\begin{tabular}{|c|c|c|c|c|c|c|c|c|}
\hline Property & R1015 & R1020 & R1025 & R1030 & R1035 & R1040 & R1045 & $\mathrm{R} 1050$ \\
\hline $\begin{array}{l}\text { Resistivity }( \pm 25 \%) \\
\text { TCR }\left(\mathrm{ppm} /{ }^{\circ} \mathrm{C}\right)-55^{\circ} \mathrm{C} \text { to } \\
\quad+125^{\circ} \mathrm{C}\end{array}$ & $\begin{array}{l}30 \Omega / \mathrm{sq} \\
+150 \pm 50\end{array}$ & $\begin{array}{l}100 \Omega / \mathrm{sq} \\
+25 \pm 50\end{array}$ & $\begin{array}{l}300 \Omega / \mathrm{sq} \\
-50 \pm 50\end{array}$ & $\begin{array}{l}1 \mathrm{~K} \Omega / \mathrm{sq} \\
-75 \pm 50\end{array}$ & $\begin{array}{l}3 \mathrm{~K} \Omega / \mathrm{sq} \\
-150 \pm 50\end{array}$ & $\begin{array}{l}10 \Omega / \mathrm{sq} \\
-200 \pm 50\end{array}$ & $\begin{array}{l}30 \mathrm{~K} \Omega / \mathrm{sq} \\
-250 \pm 50\end{array}$ & $\begin{array}{l}100 \mathrm{~K} \Omega / \mathrm{sq} \\
-300 \pm 50\end{array}$ \\
\hline $\begin{array}{l}\text { High temp. stability } \\
\quad\left(10,000 \mathrm{hrs} @ 150^{\circ} \mathrm{C}\right) \Delta \mathrm{R}\end{array}$ & $<0.5 \%$ & $<0.5 \%$ & $<0.5 \%$ & $<0.5 \%$ & $<0.5 \%$ & $<0.5 \%$ & $<0.5 \%$ & $<0.5 \%$ \\
\hline $\begin{array}{l}\text { Load stability }(10,000 \mathrm{hrs} \\
\left.\quad @\left\{25 \mathrm{~W} / \mathrm{in}^{2}\right\} @ 70^{\circ} \mathrm{C}\right) \Delta \mathrm{R}\end{array}$ & $<0.5 \%$ & $<0.5 \%$ & $<0.5 \%$ & $<0.5 \%$ & $<0.5 \%$ & $<0.5 \%$ & $<0.5 \%$ & $<0.5 \%$ \\
\hline $\begin{array}{l}\text { Moisture resistance (six } \\
\text { damp head cycles) } \Delta R\end{array}$ & $<0.5 \%$ & $<0.5 \%$ & $<0.5 \%$ & $<0.5 \%$ & $<0.5 \%$ & $<0.5 \%$ & $<0.5 \%$ & $<0.5 \%$ \\
\hline
\end{tabular}

are summarised in Table I. A more detailed picture of the rate of change in resistance at elevated temperatures and on load, for totally unprotected resistors over a period of 10,000 hours is given in Figures 1 and 2 .

The resistance values available $(30 \Omega / \mathrm{sq}-100 \mathrm{~K} \Omega / \mathrm{sq})$ covers the useful range required for most applications. The temperature coefficient of resistance (TCR) is within $250 \mathrm{ppm} /{ }^{\circ} \mathrm{C}$ except at the top end of the range and the TCR tracking is particularly close being generally within $10 \mathrm{ppm}$ for resistors printed from the same batch of paste. Laser trimming is readily accomplished with a clean kerf and the post-trim stability is little affected. Stability at high temperatures is outstanding, changes in resistance of unprotected resistors after 1000 hours at $250^{\circ} \mathrm{C}$ being less than $1 \%$. Thus it is concluded that the resistors conform to a highly satisfactory specification.

\section{PASTE PROCESSING CHARACTERISTICS}

A conventional vehicle system is used in the pastes but the absence of any heavy precious metal compounds leads to a low density material and the paste coverage (print area per gm of paste) is therefore high.

Firing cycles of widely varying length can be used. The firing cycle can be exceptionally fast, total firing cycles as short as 10 minutes have been successfully used, and it is not essential to dry the prints before firing. A typical 15 minute firing profile is shown in Figure 3 with a peak at $750^{\circ} \mathrm{C}$. The profile is bellshaped, there being no need to incorporate the usual long flat zone at the peak temperature. This simplifies furnace profiling. The effect of changes in peak firing temperature on resistivity is shown in Figure 4.

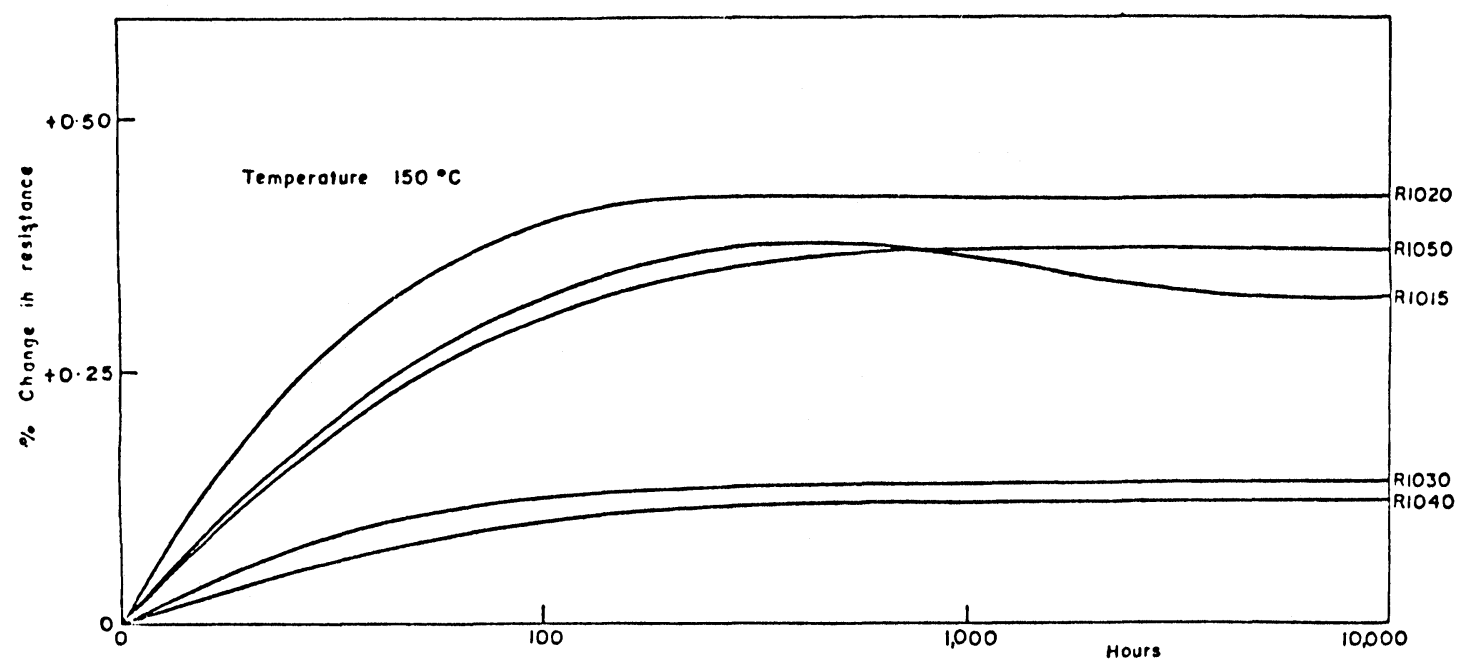

FIGURE 1 Stability after high temperature exposure. 


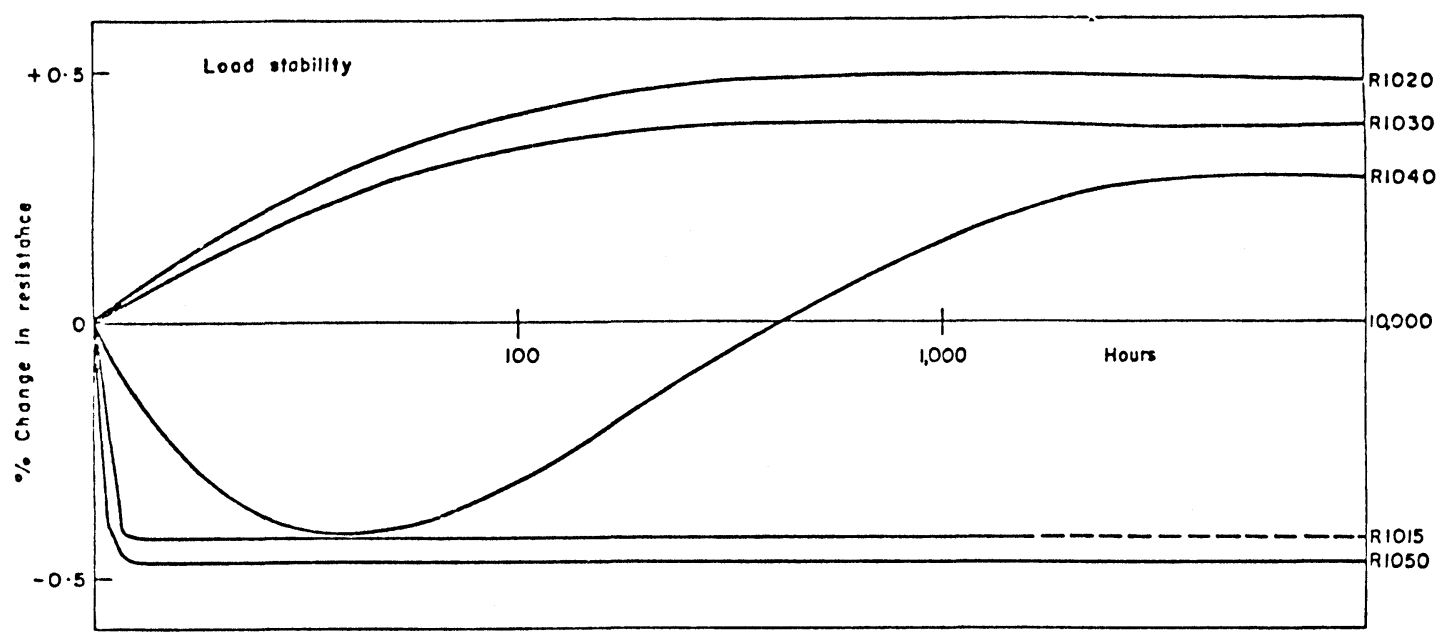

FIGURE 2 Power level of $25 \mathrm{~W} / \mathrm{in}^{2}$ at ambient of $70^{\circ} \mathrm{C}$ (R1050 derated to $500 \mathrm{~V} /$ in level.

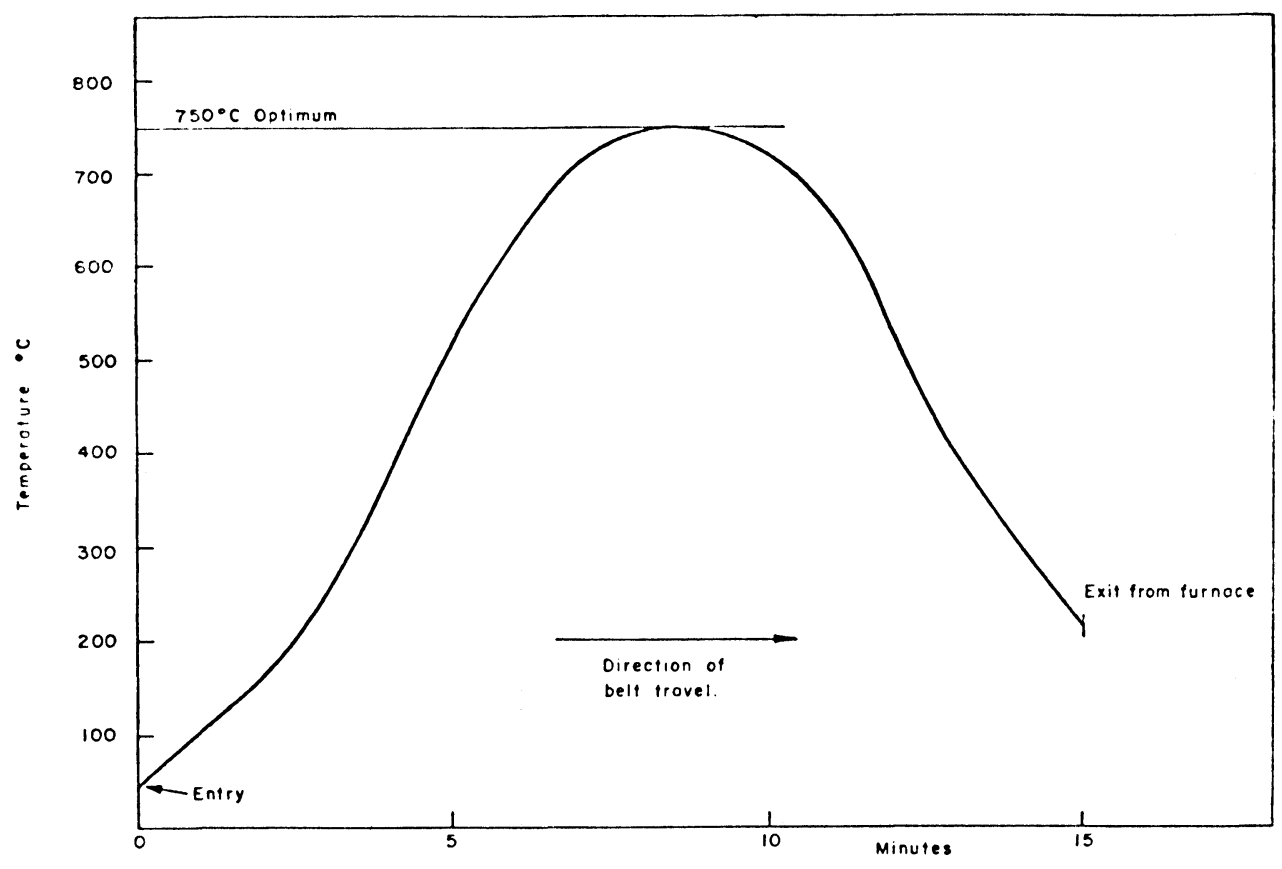

FIGURE 3 Firing profile.

The curves are of unusual form and show that the resistivity passes through a minimum near $750^{\circ} \mathrm{C}$ for compositions of all values. This means that provided the firing conditions are set close to this minimum the firing temperature sensitivity is very low. Small changes in temperature near the minimum do not affect the TCR appreciably.

\section{CONDUCTOR TERMINATIONS}

The resistors can be terminated with conductors of all of the conventional precious metal types: gold, platinum-gold, palladium-gold, palladium-silver and platinum-silver. However, for economic reasons the emphasis in assessment has been on the use of pal- 


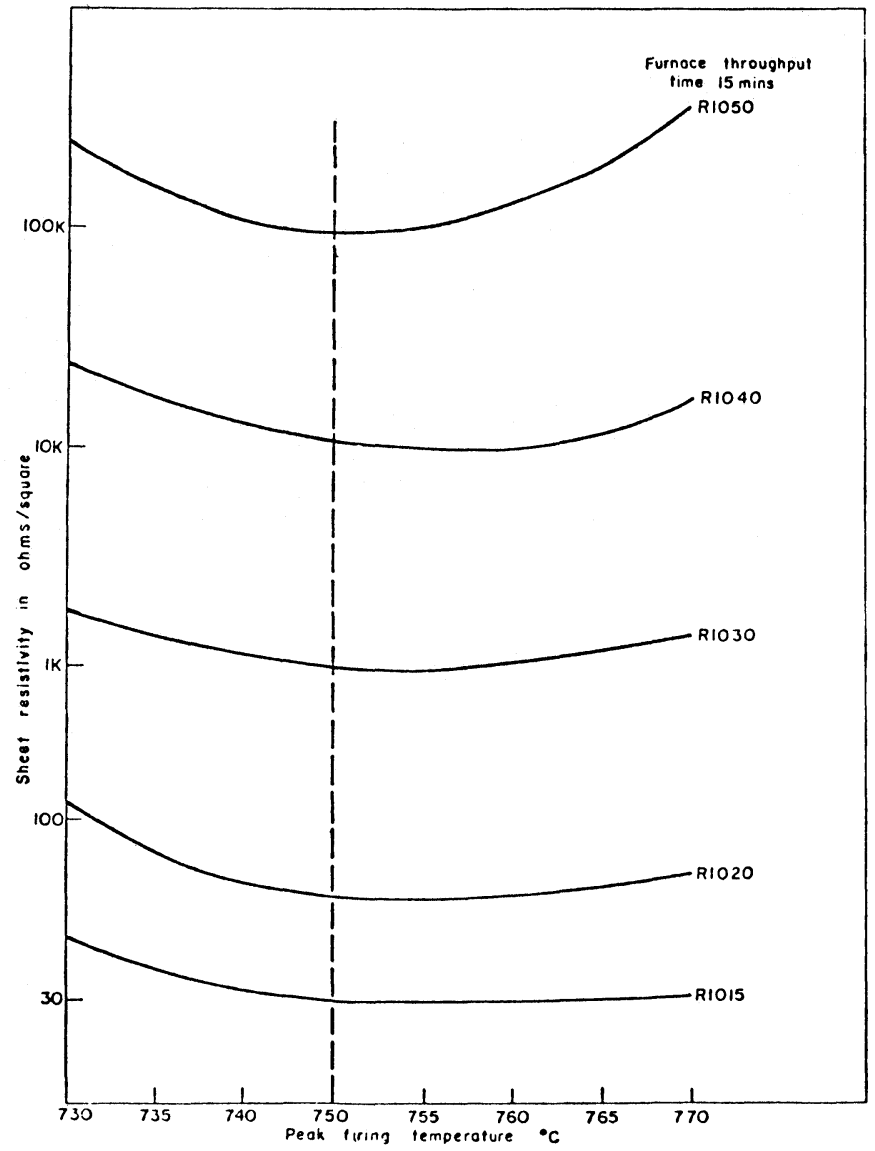

FIGURE 4 Variation of sheet resistivity with firing temperature ${ }^{\circ} \mathrm{C}$.

ladium silver conductors of relatively high silver content. These proved to be particularly suitable. The resistors are remarkably free from 'end effects' attributable either to the presence of interfacial layers at the conductor/resistor overlap causing a positive contact resistance, or to diffusion of metal from the conductor into the resistor causing a reduction in value or 'negative contact resistance'. These effects are commonly observed, sometimes to a very marked degree, in ruthenium-based resistor systems. This freedom from serious end effects is evident from the data illustrated in Figure 5 which shows the variation of apparent sheet resistance with resistor length. The only noticeable effect is a very slight increase in apparent sheet resistance for very short resistors at the $100 \mathrm{Kohm} / \mathrm{square}$ level.

The above data was obtained using palladium-silver conductors. More recently assessment of terminations prepared from air-firing nickel compositions has been

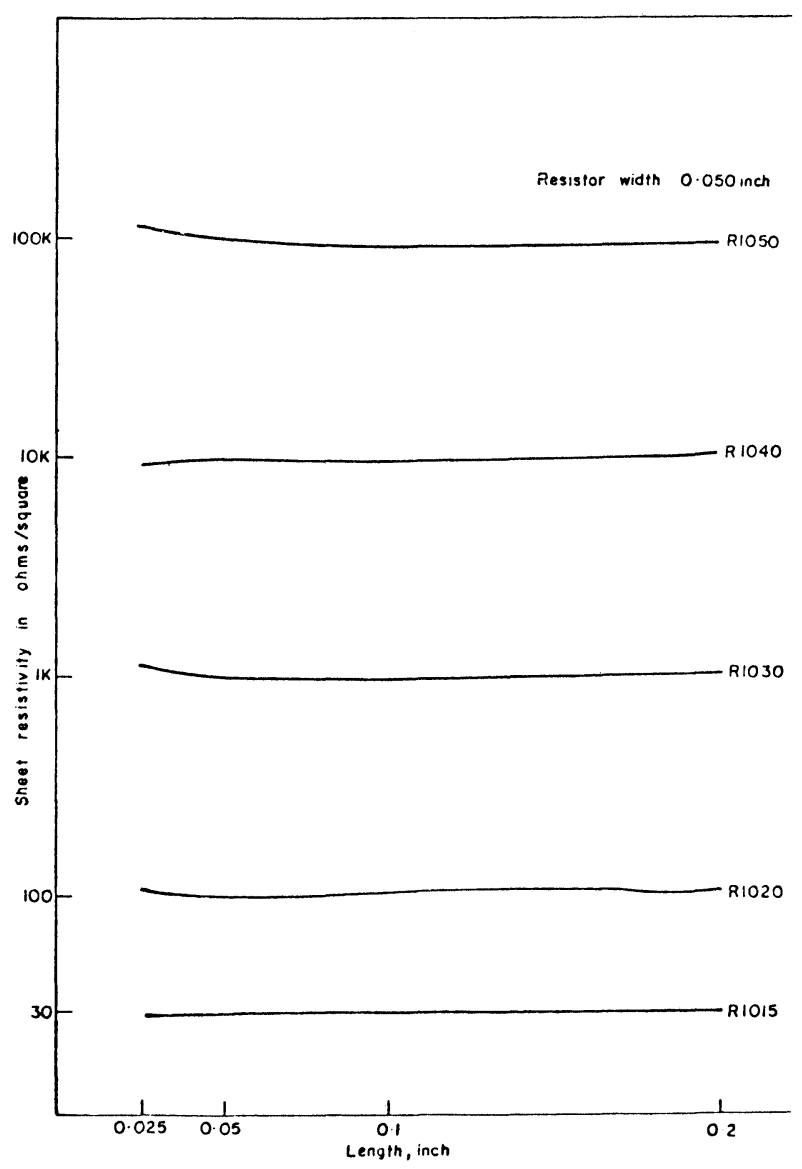

FIGURE 5 Variation of resistivity with resistor length.

undertaken. Preliminary results are very encouraging. Table II shows the results of co-firing nickel conductors with Electrofilm base metal resistors in a 15 minute firing cycle, peak temperature of $750^{\circ} \mathrm{C}$, in air. The tests were carried out using pastes of two nominal values $100 \Omega$ /square and $100 \mathrm{~K} \Omega /$ square.

The results show that over a wide range of resistor length the apparent resistivity remains essentially constant indicating an almost-total absence of end effects. This is confirmed by visual examination which reveals no sign of undesirable interactions at the interface between conductor and resistor. Similar results were obtained with pre-fired conductors. Measured TCR's are similar to those obtained using palladium-silver conductors. Short term load and dry heat exposure tests are highly satisfactory and the consistency of as-fired values and absence of 'end effects' give grounds for expecting long term behaviour at least as good as that obtained with palladium silver terminations. Indeed the 
TABLE II

\begin{tabular}{llllllll}
\hline $\begin{array}{l}\text { Resistor size length } \times \text { width } \\
\text { (inches) }\end{array}$ & $\begin{array}{l}0.2 \times \\
\text { inc }\end{array}$ & $\begin{array}{l}0.05 \times \\
0.05\end{array}$ & $\begin{array}{l}0.016 \times \\
0.05\end{array}$ & $\begin{array}{l}0.025 \times \\
0.05\end{array}$ & $\begin{array}{l}0.1 \times \\
0.05\end{array}$ & $\begin{array}{l}0.1 \times \\
0.1\end{array}$ & $\begin{array}{l}0.1 \times \\
0.13\end{array}$ \\
\hline $\begin{array}{l}\text { Mean value of ten resistors } \\
\text { printed with R1020 }\end{array}$ & $464 \Omega$ & $105 \Omega$ & $30.3 \Omega$ & $57 \Omega$ & $230 \Omega$ & $113 \Omega$ & $149 \Omega$ \\
$\begin{array}{c}\text { Mean normalised value in } \\
\quad \Omega / \square\end{array}$ & 116 & 105 & 91 & 114 & 115 & 113 & 112 \\
$\begin{array}{c}\text { Mean value of ten resistors } \\
\text { printed with R1050 }\end{array}$ & $456 \mathrm{~K} \Omega$ & $105 \mathrm{~K} \Omega$ & $23.3 \mathrm{~K} \Omega$ & $47.5 \mathrm{~K} \Omega$ & $218 \mathrm{~K} \Omega$ & $110 \mathrm{~K} \Omega$ & $136 \mathrm{~K} \Omega$ \\
$\begin{array}{c}\text { Mean normalised value in } \\
\mathrm{K} \Omega / \square\end{array}$ & 114 & 107 & 70 & 95 & 109 & 110 & 102 \\
\hline
\end{tabular}

absence of a highly mobile ionic species such as silver in the nickel conductor gives further grounds for confidence in the absence of long-term degradation.

The fast, relatively low temperature firing cycle used for the base metal resistors is well suited to the airfiring of nickel conductors. The conductivity obtained is fairly high ( $<0.05 \mathrm{ohms} /$ square) and the adhesion is good. The conductors are readily solderable with normal tin-lead solders after a mild cleaning operation to remove surface contamination.

\section{CONCLUSION}

An air-firing base metal resistor and conductor system which has characteristics suitable for the manufacture of thick film circuits has been developed. The savings in material costs compared to precious metal alternatives together with fast firing in conventional furnaces make the system attractive for low cost high volume applications.

\section{ACKNOWLEDGEMENTS}

It is a pleasure to thank colleagues N. Davey who contributed to the research programme, and C. Stringer who carried out much experimental work.

\section{REFERENCE}

1. A. S. Laurie, A High Quality Base Metal, Thick Film Resistor System, IEEE Electronic Components Conference, Washington D.C. 137-139 (May, 1973). 

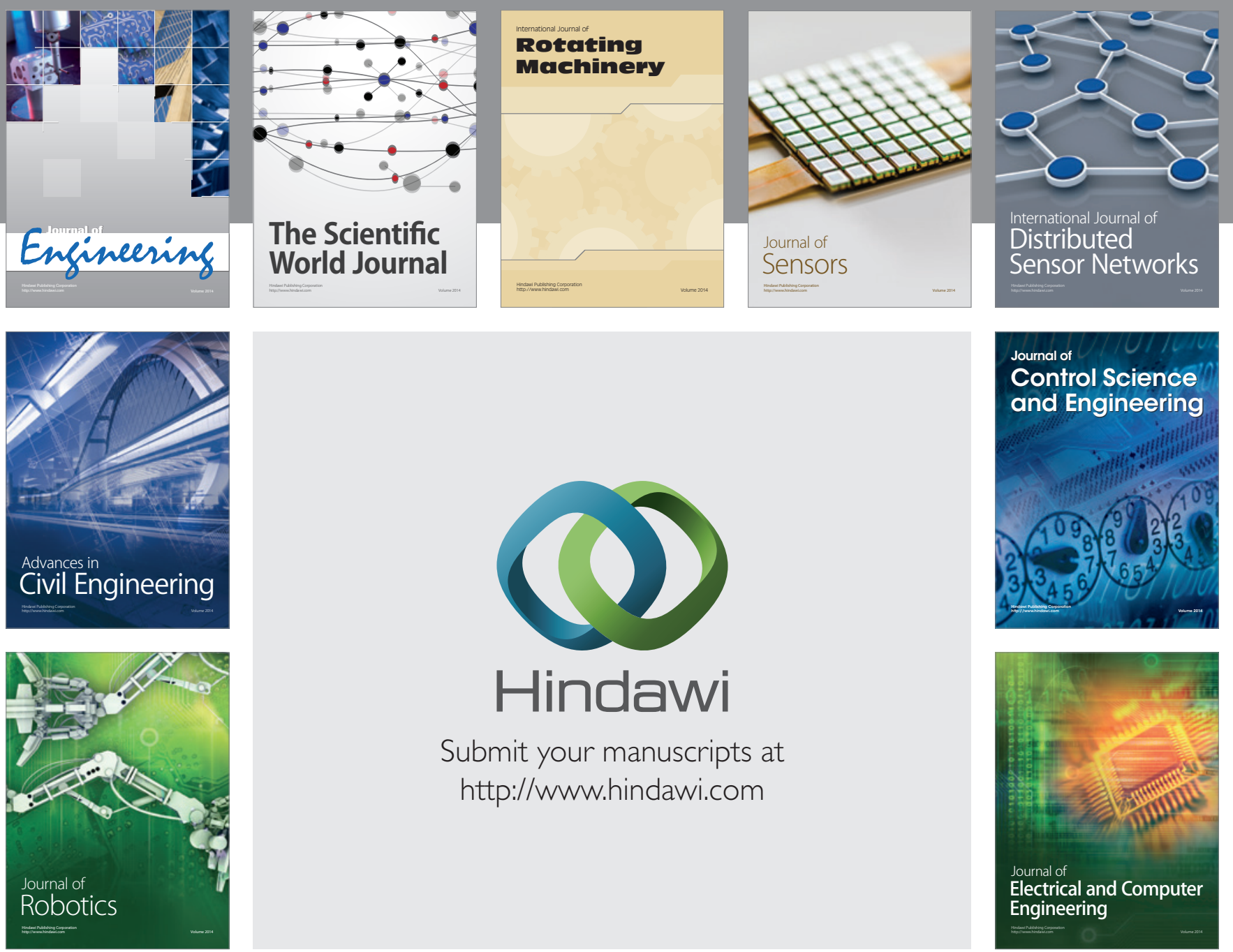

Submit your manuscripts at

http://www.hindawi.com
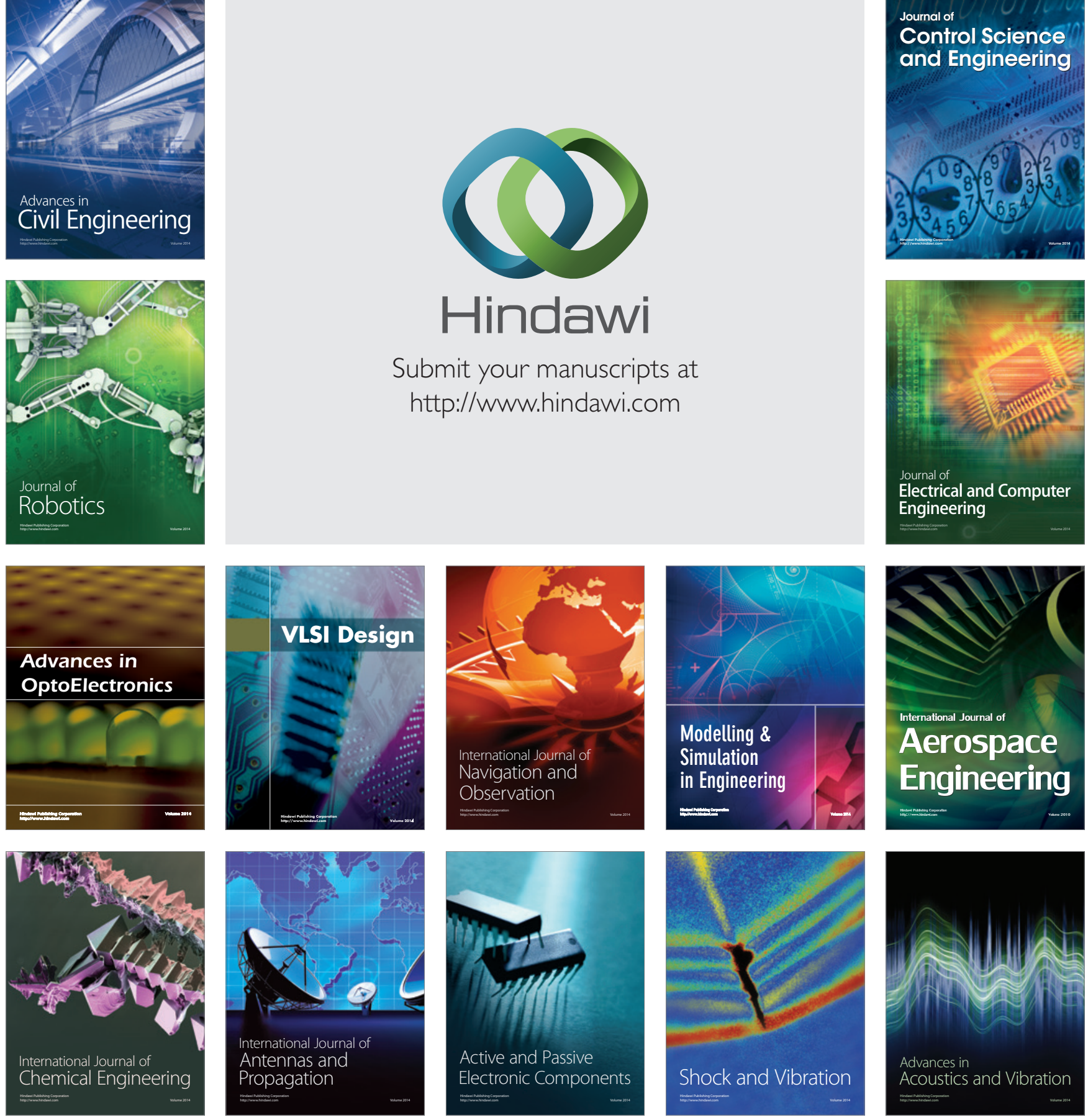